\title{
Biochar from Alpaca Manure, The Basics
}

\author{
Donald R. Sutton ${ }^{1}$, Olivia M. Vierrether ${ }^{1}$, Kassandra E. Anderson ${ }^{2}$ and Clarissa A. Wisner ${ }^{3}$ \\ ${ }^{1 .}$ Sutton At Home Alpaca Farm, Rolla, MO, USA. \\ 2. DKPE Engineering, Columbia, MO, USA. \\ 3. Missouri University of Science and Technology, Graduate Center for Materials Research, Rolla, MO, \\ USA.
}

Waste management has been identified as an ongoing concern for livestock farms. For livestock farms/producers/stables waste management is an important part of the daily operation. Common practice for waste management is to remove and stockpile the waste away from the areas occupied by animals. These stockpiles are known to leach nitrogen $(\mathrm{N})$ and other potentially harmful elements into the soil, and in the end, groundwater.[1] Innovative use of biochar has been proven to reduce $\mathrm{N}$ loss from animal waste, enhance the availability of $\mathrm{N}$ mineralization in soils, improve and sustain soil quality and fertility, and increase crop growth.[2] Biochar is the product of pyrolysis of a biomass feedstock at elevated temperatures in the absence of oxygen. The small livestock producer needs an alternative to the "stockpile" waste management which can be accomplished with minimal change to the daily farming tasks. Open air burning of the waste is a viable alternative to stockpile management but adds to the quantity of particulates in the air. Use of a biochar reactor to turn farm waste (manure/biomass) into biochar for the addition and enhancement of soil is a reasonable alternative to the stockpiling method.

Initial characterizations were conducted with alpaca manure (camelid) due to its availability and easy handling. Three samples were examined, dehydrated manure (DM), open air combustion manure (OM), and pryolyzed manure (PM). The DM sample, alpaca manure, was placed in a lab oven for 24 hours to remove all moisture. The PM sample was heated in a laboratory furnace at $400^{\circ} \mathrm{C}$ for 8 hours and cooled to room temperature. The OM sample was taken from a manure stockpile that had been burning for approximately 4 days. Elemental analysis, EDS, was conducted on all three samples, Table 1. Pyrolysis enhanced the concentration of $\mathrm{Mg}, \mathrm{Si}, \mathrm{P}$ and $\mathrm{Ca}$ in the final material with respect to the DM sample. Whereas the OM sample contained higher elemental concentrations of $\mathrm{Al}, \mathrm{Si}, \mathrm{K}$, and $\mathrm{Ca}$ with the addition of $\mathrm{Fe}$. The main dissimilarity between the three samples are the $\mathrm{C}$ and $\mathrm{O}$ concentrations, the $\mathrm{DM}$ and PM contained relatively the same concentration of $\mathrm{C}(\sim 50 \mathrm{wt}$. \%) with the OM sample much less $(\sim 11$ wt. \%). The $\mathrm{O}$ concentration is decreased in the PM but increased in the OM. For a soil amendment the main interests are the N, P, and K values. Compared to a NPK fertilizer, 10-10-10, the $\mathrm{DM}$ and PM samples are much less in the N, P, and K concentrations, thus PM can be used for soil amendment but cannot be considered a fertilizer. Use of DM as soil amendment is also a viable option but inorganic-N leaching is a concern.[3]

SEIs of DM, PM, and OM show the original vascular structure of the undigested feed (hay), Figures 1AC. The original vascular structures are more prominent in the DM and PM samples. These features, created by escaping gases and existing pore structures produce a highly porous material. Retention of the original vascular structure allows for ease of liquid infiltration and gaseous transportation processing of materials when mixed with the soils. Future work will include the construction of a "backyard" biochar reactor as well as pore characterization and comparison of the manure biochar material (laboratory and reactor) to that of commercially available activated carbon. Specifics will focus on the use of biochar as a filtration media for removal of water contaminants and soil amendment details. 
References:

[1] M. Callisto et al, in "Eutrophication: Causes, Consequences and Control", ed. A. A. Ansari and S. S. Gill, (Springer, Dordrecht Heidelberg London New York) p. 55.

[2] T. J. Clough et al, Agronomy 3 (2013), p. 275.

[3] B. P. Singh et al, J. Environ. Qual. 39 (2010), p. 1224.

Table 1. Elemental analysis of alpaca manure processing products, wt.\%.

\begin{tabular}{llllllllllll} 
Sample & $C$ & $N$ & $O$ & $M g$ & $A l$ & $S i$ & $P$ & $S$ & $K$ & $C a$ & $F e$ \\
\hline$D M$ & 50.3 & 3.1 & 35.3 & 1.5 & 0.3 & 4.1 & 1.0 & 0.5 & 1.4 & 2.5 & nd* \\
$P M$ & 48.1 & 2.8 & 27.4 & 4 & 0.5 & 9.2 & 2.1 & nd & 1.1 & 4.8 & nd \\
OM & 11.3 & nd & 45.1 & 3.7 & 4.1 & 19.1 & 1.7 & nd & 4.1 & 8.7 & 1.3
\end{tabular}

*nd $=$ None detected
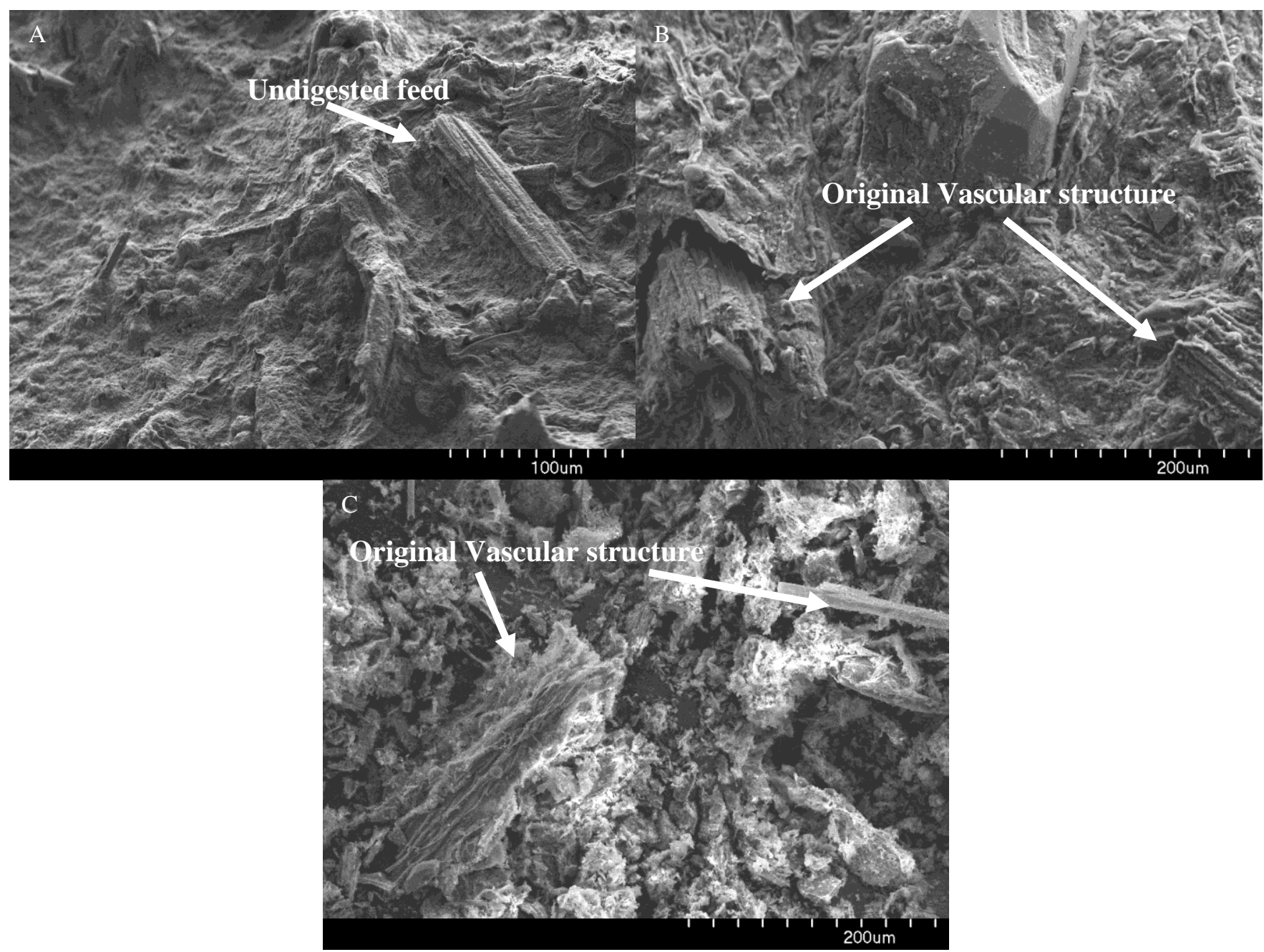

Figure 1. A) DM sample with undigested feed, B) PM sample with the original vascular plant structures visible, C) OM sample with barely discernable vascular plant structures visible. 